Int. J. Electrochem. Sci., 16 (2021) Article ID: 210725

International Journal of

ELECTROCHEMICAL

SCIENCE

www.electrochemsci.org

Mini review

\title{
Research Progress in Electrochemical, Electrochemiluminescent and Photoelectrochemical Detection of Histone Acetyltransferase
}

\section{Xiaohua Ma}

Henan Key Laboratory of Biomolecular Recognition and Sensing, College of Chemistry and Chemical Engineering, Shangqiu Normal University, Shangqiu, Henan 476000, People's Republic of China E-mail: maxhsqnu@aliyun.com

doi: $10.20964 / 2021.07 .55$

Received: 18 March 2021 / Accepted: 9 May 2021 / Published: 31 May 2021

Changes in the level and activity of histone acetyltransferase (HAT) have been shown to be associated with the pathogenesis of many diseases. Electrochemical techinques have the advantages of low cost, miniaturization, real-time monitoring and good selectivity as well as sensitivity. Herein, we summarized the research progress in electrochemistry-related methods for the detection of HAT activity, including electrochemistry, electrochemiluminescence and photoelectrochemistry.

Keywords: Histone acetyltransferase; post-translational modification; electrochemistry; electrochemiluminescence; photoelectrochemistry

\section{FULL TEXT}

(C) 2021 The Authors. Published by ESG (www.electrochemsci.org). This article is an open access article distributed under the terms and conditions of the Creative Commons Attribution license (http://creativecommons.org/licenses/by/4.0/). 